\title{
Association of the Geriatric Nutritional Risk Index with the survival of patients with non-small-cell lung cancer after platinum-based chemotherapy
}

Masato Karayama ( $\sim$ karayama@hama-med.ac.jp )

Hamamatsu University School of Medicine

Yusuke Inoue

Hamamatsu University School of Medicine

Hideki Yasui

Hamamatsu University School of Medicine

Hironao Hozumi

Hamamatsu University School of Medicine

Yuzo Suzuki

Hamamatsu University School of Medicine

Kazuki Furuhashi

Hamamatsu University School of Medicine

Tomoyuki Fujisawa

Hamamatsu University School of Medicine

Noriyuki Enomoto

Hamamatsu University School of Medicine

Yutaro Nakamura

Hamamatsu University School of Medicine

Naoki Inui

Hamamatsu University School of Medicine

Takafumi Suda

Hamamatsu University School of Medicine

\section{Research Article}

Keywords: albumin, cachexia, hypoalbuminemia, malnutrition, nutrition

Posted Date: October 22nd, 2021

DOI: https://doi.org/10.21203/rs.3.rs-948188/v2 
License: (c) (i) This work is licensed under a Creative Commons Attribution 4.0 International License. Read Full License

Version of Record: A version of this preprint was published at BMC Pulmonary Medicine on December 1st, 2021. See the published version at https://doi.org/10.1186/s12890-021-01782-2. 


\section{Abstract \\ Background}

The nutritional status can potentially affect the efficacy of cancer therapy. We evaluated the relationships between the nutritional status and the efficacy of chemotherapy in patients with non-small-cell lung cancer (NSCLC).

\section{Methods}

The Geriatric Nutritional Risk Index (GNRI), calculated from body weight and serum albumin, was retrospectively evaluated in 148 patients with NSCLC who received first-line platinum-based chemotherapy and scored as low or high.

\section{Results}

Patients with a high GNRI had a significantly higher overall response rate (ORR; 61.8\% [95\% confidence interval $\{\mathrm{Cl}\}=52.5-70.3 \%]$ vs. $34.2 \%[95 \% \mathrm{Cl}=21.2-50.1 \%, p<0.004)$, longer median progression-free survival (PFS; 6.3 months $[95 \% \mathrm{Cl}=5.6-7.2$ months] vs. 3.8 months $[95 \% \mathrm{Cl}=2.5-4.7$ months], $p<$ 0.001 ), and longer median overall survival (OS; 22.8 months $[95 \% \mathrm{Cl}=16.7-27.2$ months] vs. 8.5 months [95\% Cl $=5.4-16.0$ months], $p<0.001$ ) than those with low GNRI. High GNRI was independently predictive of longer PFS and OS, but not ORR, in multivariate Cox proportional hazard analyses. In 71 patients who received second-line non-platinum chemotherapy, patients with high GNRI exhibited significantly longer PFS and OS than those with low GNRI (both $p<0.001$ ).

\section{Conclusions}

GNRI was predictive of prolonged survival in patients with NSCLC who received first-line platinum-based chemotherapy and second-line non-platinum chemotherapy. Assessment of the nutritional status may be useful for predicting the efficacy of chemotherapy.

\section{Introduction}

Novel anti-cancer agents, such as oncogene-targeted drugs and immune checkpoint inhibitors (ICls), have dramatically changed cancer therapy in recent decades. Meanwhile, the nutritional status is universally important for improving outcomes in patients with cancer. The associations between the nutritional status and prognosis are well established in a wide variety of non-cancer diseases, but they are particularly prominent in advanced cancer [1-5]. For example, cancer cachexia, characterized by the loss of body weight and lean body mass, leads to decreased quality of life, reduced chemotherapy tolerance, reduced physical function, and shortened survival [6-9]. Recently, anamorelin, a novel oral ghrelin 
receptor agonist, was revealed to improve cancer cachexia, and it has been approved for clinical use in patients with several cancers [10]. The nutritional status has been attracted renewed attention in cancer therapy.

The nutritional status does not merely represent a vague health status, but it is also associated with the mechanisms underlying tumor growth, anti-tumor activity of cancer therapy, or resistance to cancer therapy. For example, fat tissue-associated factors, such as leptin, fatty acids, and pro-inflammatory cytokines, contribute to cancer immunity [11]. In addition, serum albumin binds to chemotherapeutic agents and delivers them to tumor tissues [12-14]. The clinical benefits of cancer therapy are achieved through both effective anti-cancer therapy and preservation of the host status. Thus, the nutritional status can potentially predict the efficacy of cancer therapy.

The Geriatric Nutritional Risk Index (GNRI), a simple index for evaluating nutritional status calculated from body weight and serum albumin levels, has been reported to be useful for predicting the prognosis of various diseases, including infectious and chronic diseases [15-19]. In cancer therapy, the GNRI is reported to be associated with the clinical outcomes of surgery, chemotherapy, or chemoradiotherapy in a wide variety of cancers [20-22]. However, little is known about the association of the GNRI with the efficacy of chemotherapy in non-small-cell lung cancer (NSCLC). Albumin, a component of the GNRI, in addition to playing an important role in the delivery of anti-cancer agents to tumor tissue, can also inhibit immunosuppression in the tumor microenvironment [23-26]. Body weight, the other component of the GNRI, is associated with cancer immunity in the tumor microenvironment via factors associated with fat tissue [11]. Thus, the GNRI might be predictive of the efficacy of chemotherapy. The current study evaluated the pretreatment GNRI and its associations with the efficacy of first-line platinum-based chemotherapy and second-line non-platinum chemotherapy in patients with NSCLC.

\section{Patients And Methods \\ 2.1. Study design}

This was a retrospective observational study conducted in accordance with the ethical standards of the Declaration of Helsinki. Patients with advanced NSCLC who received first-line platinum-based chemotherapy at Hamamatsu University Hospital between January 1, 2000 and December 31, 2020 were included. Patients who received non-platinum therapy in the first-line setting, those with histories of previous chemotherapy, or those missing pretreatment serum albumin and body weight data were excluded. Patient consent was waved because this was a retrospective study. The study protocol was approved by the Institutional Review Board of Hamamatsu University School of Medicine (No. 21-151).

\subsection{Data collection}

Clinical data including age, sex, smoking status, height, weight, serum albumin levels before the administration of platinum-based chemotherapy, tumor histology, active driver mutations, clinical stage, Eastern Cooperative Oncology Group performance status (ECOG-PS), and treatment regimens were 
retrospectively evaluated via medical record review. Response was assessed using Response Evaluation Criteria in Solid Tumors version 1.1. Progression-free survival (PFS) and overall survival (OS) were evaluated from the time of treatment initiation.

\subsection{Measurements of the Geriatric Nutritional Risk Index}

The GNRI was calculated as follows:

GNRI $=[1.489 \times$ serum albumin $(\mathrm{g} / \mathrm{dL})]+[41.7 \times$ actual weight $/$ ideal weight $][15]$.

Ideal weight was calculated using body mass index as follows:

Ideal weight $=22 \times[\text { height }(\mathrm{m})]^{2}$.

Originally, the GNRI was divided into four levels: $<82, \geq 82$ to $<92, \geq 92$ to $<98$, and $\geq 98$ [15]. However, in the current study, the GNRI was categorized as low $(<92)$ or high $(\geq 92)$ because the overall response rate (ORR), PFS, and OS did not differ among the four GNRI categories (Supplementary Figure 1).

\subsection{Statistical analyses}

Fisher's exact test and Wilcoxon's rank sum test were used to compare categorical and continuous variables, respectively. Pearson's correlation coefficient was used to evaluate the correlations between age and the GNRI. The Jonckheere-Terpstra trend test was used to evaluate the trend between the GNRI and ECOG-PS. Wilcoxon's signed-rank sum test was used to compare the GNRI between first- and secondline therapy. PFS and OS were evaluated using the Kaplan-Meier method, and the log-rank test was used to compare survival curves. Logistic regression analysis was used to determine predictive factors for ORR, and Cox proportional hazard analysis was used to determine predictive factors for PFS and OS. The variables significant at $p<0.100$ in univariate analyses were employed for multivariate analyses. $p<0.05$ (two-sided) denoted significance. All values were analyzed using JMP v13.2.0 (SAS Institute Japan, Tokyo, Japan), excluding the Jonckheere-Terpstra test, which was performed using EZR (Saitama Medical Center, Jichi Medical University, Saitama, Japan), a graphical user interface for R (The R Foundation for Statistical Computing, Vienna, Austria).

\section{Results}

\subsection{Patient characteristics}

In total, 148 patients were included in this study. The characteristics of the patients are presented in Table 1. The cohort had a high proportion of men (73.6\%), smoking history $(75.0 \%)$, and good ECOG-PS of 0-1 (89.2\%). Sixty-seven (45.2\%) patients were $\geq 65$ years old. Ninety-five (64.1\%) patients had normal BMI $\left(\geq 18.5\right.$ to $\left.<25.0 \mathrm{~kg} / \mathrm{m}^{2}\right)$, and $26(17.6 \%)$ and 27 patients (18.2\%) were underweight and overweight, respectively. The median GNRI was 100.6 (range, 56.6-124.6), and 19 (12.8\%), 19 (12.8\%), 22 (14.9\%), and $88(59.5 \%)$ patients had GNRIs of $<82, \geq 82$ to $<92, \geq 92$ to $<98$, and $\geq 98$, respectively. All patients 
received at least one cycle of platinum-based chemotherapy, and 119 (80.4\%) and 29 patients (19.6\%) received carboplatin and cisplatin, respectively. Concerning combination regimens featuring platinum agents, 61 (41.2\%), 58 (39.1\%), and 29 patients (19.6\%) received pemetrexed, taxanes, and other agents, respectively.

Table 1

Patient characteristics

\begin{tabular}{|c|c|}
\hline & $N=148$ \\
\hline Age, years & $65(36-84)$ \\
\hline Sex, men & $109(73.6)$ \\
\hline Smoking status, ever-smoker & $111(75.0)$ \\
\hline ECOG-PS, 0/1/ $\geq 2$ & $90(60.8) / 42(28.3) / 16(10.8)$ \\
\hline Body mass index, $\mathrm{kg} / \mathrm{m}^{2}$ & $21.9(13.7-30.5)$ \\
\hline Serum albumin (g/dL) & $3.7(2.1-4.9)$ \\
\hline Geriatric nutritional risk index & $100.6(56.6-124.6)$ \\
\hline Stage, IIlb/IV/recurrence & $20(13.5) / 127(85.8) / 1(0.7)$ \\
\hline Pathology, adeno/squamous/others & $88(59.5) / 39(26.4) / 21(14.2)$ \\
\hline EGFR mutation, positive/wild-type/unknown & $16(10.8) / 101(68.2) / 31$ (20.9) \\
\hline$A L K$ fusion gene, positive/wild-type/unknown & $1(0.7) / 73(49.3) / 74(50.0)$ \\
\hline Chemotherapy regimens & $54(36.5)$ \\
\hline Carboplatin/(nab-)paclitaxel \pm bevacizumab & $45(30.4)$ \\
\hline Carboplatin/pemetrexed \pm bevacizumab & $16(10.8)$ \\
\hline Cisplatin/pemetrexed \pm bevacizumab & $20(13.5)$ \\
\hline Other cisplatin-based therapy & $13(8.8)$ \\
\hline \multicolumn{2}{|l|}{ Other carboplatin-based therapy } \\
\hline Data are expressed as the median (interquartile & nber (\%). \\
\hline
\end{tabular}

Thirty-one patients $(20.9 \%)$ received bevacizumab in addition to platinum-based chemotherapy. The overall ORR was $54.7 \%$ (95\% confidence interval $[\mathrm{Cl}]=46.7-62.5 \%$ ), and median PFS and OS were 5.6 (95\% Cl $=5.1-6.2$ months) and 17.0 months ( $95 \% \mathrm{Cl}=14.6-22.9$ months), respectively.

\subsection{Associations of the GNRI with patient demographics}


There was a significant stepwise decrease in the GNRI according to the deterioration of ECOG-PS.

Specifically, the median GNRIs (range) in the ECOG-PS 0, 1, and $\geq 2$ groups were 104.6 (65.8-124.6), 98.3 (56.6-121.7), and $82.0(69.4-112.9)$, respectively $(p<0.001)$. The GNRI was not associated with sex, age, smoking status, tumor histology, or clinical stage.

\subsection{Association of the GNRI with the efficacy of platinum- based chemotherapy}

Patients with a high GNRI had significantly longer median PFS (6.3 months, $95 \% \mathrm{Cl}=5.6-7.2$ months) than those with a low GNRI (3.8 months; $95 \% \mathrm{Cl}=2.5-4.7$ months, $p<0.001$; Figure $1 \mathrm{~A}$ ). In univariate Cox proportional hazard analyses, an increased GNRI was predictive of longer PFS, similarly as age $<65$ years, good ECOG-PS, receipt of cisplatin, and receipt of pemetrexed (Table 2). In multivariate Cox proportional hazard analyses, only an increased GNRI was an independent predictive factor for longer PFS (Table 2). 
Table 2

Cox proportional hazard analyses of progression-free survival

\begin{tabular}{|c|c|c|c|c|}
\hline & Univariate & & Multivariate & \\
\hline Variables & $\begin{array}{l}\text { Hazard ratio }(95 \% \\
\mathrm{Cl})\end{array}$ & $\begin{array}{l}p- \\
\text { value }\end{array}$ & $\begin{array}{l}\text { Hazard ratio }(95 \% \\
\mathrm{Cl})\end{array}$ & $\begin{array}{l}p- \\
\text { value }\end{array}$ \\
\hline Age, $\geq 65$ years & $1.47(1.01-2.14)$ & 0.041 & $0.63(0.38-1.10)$ & 0.102 \\
\hline Sex, men & $1.02(0.68-1.57)$ & 0.941 & & \\
\hline Smoking, ever-smoker & $1.27(0.84-1.96)$ & 0.257 & & \\
\hline ECOG-PS, & $0.71(0.47-1.09)$ & 0.114 & $1.01(0.65-1.60)$ & 0.969 \\
\hline 0 vs. 1 & $0.34(0.18-0.71)$ & 0.006 & $0.71(0.34-1.60)$ & 0.392 \\
\hline 0 vs. $\geq 2$ & $0.48(0.24-1.03)$ & 0.059 & $0.70(0.35-1.55)$ & 0.368 \\
\hline \multicolumn{5}{|l|}{1 vs. $\geq 2$} \\
\hline GNRI, $\geq 92$ & $0.28(0.18-0.46)$ & $<0.001$ & $0.33(0.20-0.56)$ & $<0.001$ \\
\hline $\begin{array}{l}\text { Pathology, squamous cell } \\
\text { (vs. non-squamous) }\end{array}$ & $1.20(0.79-1.79)$ & 0.390 & & \\
\hline Stage, IIlb (vs. IV/ recurrent) & $0.85(0.44-1.47)$ & 0.575 & & \\
\hline $\begin{array}{l}\text { Platinum agents, cisplatin (vs. } \\
\text { carboplatin) }\end{array}$ & $0.59(0.35-0.95)$ & 0.029 & $0.65(0.38-1.06)$ & 0.086 \\
\hline Non-platinum agents, & $0.62(0.41-0.95)$ & 0.028 & $0.72(0.47-1.10)$ & 0.125 \\
\hline Pemetrexed vs. taxane & $0.58(0.35-0.98)$ & 0.042 & $0.65(0.39-1.13)$ & 0.124 \\
\hline Pemetrexed vs. others & $0.93(0.57-1.55)$ & 0.781 & $0.91(0.55-1.54)$ & 0.720 \\
\hline Taxane vs. others & & & & \\
\hline
\end{tabular}

Likewise, patients with a high GNRI had significantly longer median OS (22.8 months, $95 \% \mathrm{Cl}=16.7-27.2$ months) than those with a low GNRI ( 8.5 months, $95 \% \mathrm{Cl}=5.4-16.0$ months, $p<0.001$; Figure $1 \mathrm{~B})$. In univariate Cox proportional hazard analyses, an increased GNRI was predictive of longer OS, similarly as age $<65$ years, no smoking history, and good ECOG-PS (Table 3). In multivariate Cox proportional hazard analyses, an increased GNRI was predictive of longer OS, similarly as no smoking history and good ECOG-PS (Table 3). 
Table 3

Cox proportional hazard analyses of overall survival

\begin{tabular}{|c|c|c|c|c|}
\hline & Univariate & & Multivariate & \\
\hline Variables & $\begin{array}{l}\text { Hazard ratio }(95 \% \\
\mathrm{Cl})\end{array}$ & $\begin{array}{l}p- \\
\text { value }\end{array}$ & $\begin{array}{l}\text { Hazard ratio }(95 \% \\
\mathrm{Cl})\end{array}$ & $\begin{array}{l}p \text { - } \\
\text { value }\end{array}$ \\
\hline Age, $\geq 65$ years & $1.70(1.11-2.59)$ & 0.014 & $1.46(0.94-2.27)$ & 0.093 \\
\hline Sex, men & $1.01(0.65-1.61)$ & 0.959 & & \\
\hline Smoking, ever-smoker & $1.92(1.20-3.22)$ & 0.006 & $1.71(1.04-2.91)$ & 0.034 \\
\hline ECOG-PS, & $0.67(0.43-1.07)$ & 0.096 & $0.76(0.47-1.23)$ & 0.253 \\
\hline 0 vs. 1 & $0.21(0.11-0.43)$ & $<0.001$ & $0.28(0.14-0.60)$ & 0.002 \\
\hline 0 vs. $\geq 2$ & $0.31(0.16-0.65)$ & 0.003 & $0.37(0.18-0.81)$ & 0.014 \\
\hline \multicolumn{5}{|l|}{1 vs. $\geq 2$} \\
\hline GNRI, $\geq 92$ & $0.39(0.24-0.65)$ & $<0.001$ & $0.51(0.30-0.89)$ & 0.018 \\
\hline $\begin{array}{l}\text { Pathology, squamous cell } \\
\text { (vs. non-squamous) }\end{array}$ & $1.18(0.73-1.84)$ & 0.492 & & \\
\hline Stage, IIlb (vs. IV/ recurrent) & $1.41(0.76-2.42)$ & 0.265 & & \\
\hline $\begin{array}{l}\text { Platinum agents, cisplatin (vs. } \\
\text { carboplatin) }\end{array}$ & $0.71(0.41-1.18)$ & 0.195 & & \\
\hline Non-platinum agents, & $0.84(0.54-1.31)$ & 0.437 & & \\
\hline Pemetrexed vs. taxane & $1.13(0.63-2.12)$ & 0.688 & & \\
\hline Pemetrexed vs. others & $1.35(0.76-2.53)$ & 0.319 & & \\
\hline Taxane vs. others & & & & \\
\hline
\end{tabular}

Patients with a high GNRI displayed significantly higher ORR $(61.8 \%, 95 \% \mathrm{Cl}=52.5-70.3 \%)$ than those with a low GNRI $(34.2 \%, 95 \% \mathrm{Cl}=21.2-50.1 \%, p<0.004)$. In univariate logistic regression analyses, an increased GNRI and good ECOG-PS were predictive of higher ORR; however, in multivariate Cox proportional hazard analyses, neither was predictive of the ORR (Table 4). 
Table 4

Logistic regression analyses of objective response

\begin{tabular}{|c|c|c|c|c|}
\hline & Univariate & & Multivariate & \\
\hline Variables & $\begin{array}{l}\text { Hazard ratio }(95 \% \\
\mathrm{Cl})\end{array}$ & $\begin{array}{l}p- \\
\text { value }\end{array}$ & $\begin{array}{l}\text { Hazard ratio }(95 \% \\
\mathrm{Cl})\end{array}$ & $\begin{array}{l}p- \\
\text { value }\end{array}$ \\
\hline Age, $\geq 65$ years & $0.53(0.28-1.03)$ & 0.061 & $0.55(0.27-1.09)$ & 0.088 \\
\hline Sex, men & $1.05(0.50-2.19)$ & 0.897 & & \\
\hline Smoking, ever-smoker & $1.20(0.57-2.53)$ & 0.634 & & \\
\hline ECOG-PS, & $1.24(0.59-2.60)$ & 0.570 & $0.98(0.45-2.13)$ & 0.959 \\
\hline 0 vs. 1 & & & & 0.112 \\
\hline $\begin{array}{l}0 \text { vs. } \geq 2 \\
1 \text { vs. } \geq 2\end{array}$ & $\begin{array}{l}3.63(1.01- \\
13.12)\end{array}$ & 0.049 & $\begin{array}{l}2.98(0.76- \\
11.74)\end{array}$ & 0.119 \\
\hline GNRI, $\geq 92$ & $3.11(1.44-6.74)$ & 0.004 & $2.29(0.98-5.34)$ & 0.055 \\
\hline $\begin{array}{l}\text { Pathology, squamous cell } \\
\text { (vs. non-squamous) }\end{array}$ & $0.72(0.35-1.50)$ & 0.380 & & \\
\hline Stage, IIlb (vs. IV/ recurrent) & $0.64(0.25-1.64)$ & 0.350 & & \\
\hline $\begin{array}{l}\text { Platinum agents, cisplatin (vs. } \\
\text { carboplatin) }\end{array}$ & $0.72(0.32-1.63)$ & 0.437 & & \\
\hline Non-platinum agents, & $1.25(0.61-2.59)$ & 0.541 & & \\
\hline Pemetrexed vs. taxane & $1.54(0.63-3.75)$ & 0.339 & & \\
\hline Pemetrexed vs. others & $1.23(0.50-3.00)$ & 0.649 & & \\
\hline Taxane vs. others & & & & \\
\hline $\begin{array}{l}\mathrm{Cl} \text {, confidence interval; ECOG-F } \\
\text { Geriatric Nutritional Risk Index }\end{array}$ & $\begin{array}{l}\text { Cooperative Oncolc } \\
\text { stimated }\end{array}$ & Group & erformance status; & RI, \\
\hline
\end{tabular}

Among the 148 patients who received first-line platinum-based chemotherapy, 71 (48.0\%) received second-line non-platinum therapy (2L group). Of those, 47 patients (63.6\%) received docetaxel (monotherapy, $n=42$; combination with bevacizumab, $n=6$; and combination with ramucirumab, $n=1$ ), 12 patients $(16.9 \%$ ) received S-1 (tegafur/gimeracil/oteracil potassium), 4 patients received $(5.6 \%)$ pemetrexed, and 8 patients $(11.3 \%)$ received other non-platinum monotherapies. The $2 \mathrm{~L}$ group had a median GNRI of 101.6 (range, 69.7-129.7) at the beginning of the second-line therapy, which was comparable to that at the beginning of first-line therapy $(p=0.941$; Figure 2$)$. The patients with a high 
GNRI at the beginning of second-line therapy exhibited significantly longer median PFS during secondline therapy $(3.3$ months, $95 \% \mathrm{Cl}=2.6-4.2$ months) than those with a low $\mathrm{GNRI}(1.2 \mathrm{months}, 95 \% \mathrm{Cl}=$ 0.6-2.1 months, $p<0.001$; Figure 3A). Likewise, the patients with a high GNRI at the beginning of secondline therapy displayed significantly longer median OS during second-line therapy $(18.5 \mathrm{months}, 95 \% \mathrm{Cl}=$ 11.0-28.7 months) than those with a low GNRI (4.4 months, 95\% Cl = 1.4-14.8 months, $p<0.001$; Figure $3 \mathrm{~B})$. There was no significant association between the GNRI and ORR during second-line therapy ( $p=$ $0.324)$.

On the contrary, among 77 patients who did not receive second-line chemotherapy, 59 evaluable patients had a median GNRI of 91.6 (range, 59.0-112.6) at the time of disease progression after first-line chemotherapy, which was significantly lower than that at the beginning the first-line chemotherapy $(p<$ $0.001)$ and significantly lower than that at beginning of the second-line therapy in the $2 \mathrm{~L}$ group $(p<0.001$; Figure 2).

\section{Discussion}

In the current study, we found that an increased pretreatment GNRI was significantly associated with longer PFS and OS following first-line platinum-based chemotherapy in patients with NSCLC independent of ECOG-PS. Furthermore, the GNRI did not change in patients who received second-line chemotherapy until the start of second-line chemotherapy, and the pretreatment GNRI was significantly associated with longer PFS and OS following second-line non-platinum chemotherapy. The GNRI is a simple modality for assessing the nutritional status of patients with cancer. Our data indicated the potential utility of the GNRI for predicting the efficacy of chemotherapy.

Albumin, a component of the GNRI, has several beneficial functions for chemotherapy. After injection into blood, platinum agents bind to albumin and form platinum-albumin complexes. Albumin delivers platinum agents efficiently to tumor tissue via these complexes. Albumin also protects against platinumassociated toxicities by reducing the levels of albumin-free platinum agents that induce cytotoxicity [1214]. In addition, albumin is known to have immunomodulatory functions in tumor microenvironments. Albumin inhibits tumor progression by reducing excessive inflammatory responses by tumor-associated neutrophils [23-26]. Furthermore, albumin reduces oxidative stress in tumor microenvironments via its anti-oxidant properties $[23,24]$. Oxidative stress induces immunosuppression in tumor microenvironments by altering cytokine signaling, increasing immunosuppressive immune cell activity, and attenuating cytotoxic lymphocytes, resulting in tumor-favorable immunity [27, 28]. It is reported that the Prognostic Nutritional Index, which is calculated using serum albumin and the peripheral blood lymphocyte count, is positively correlated with tumor-infiltrating lymphocyte counts in surgically resected esophageal cancer and squamous cell lung cancer specimens [29,30].

Body weight is an important component of cancer cachexia. In addition to the reduction of adipose tissue, the loss of muscle mass is also a cause of weight loss in patients with cancer, resulting in functional impairments and increased mortality [6-9]. In addition, reduced food intake, which both a 
cause and consequence of cancer cachexia, leads to the deprivation of essential nutrients, some of which are reported to potentially enhance anti-tumor immunity [5, 31-33]. Furthermore, systemic inflammation and metabolic changes, the underlying mechanisms of cancer cachexia, attenuate anti-tumor immunity and promote tumor progression $[34,35]$. Body weight loss attributable to cancer cachexia reflects the attenuation of anti-tumor immunity and decreases the therapeutic efficacy of chemotherapy.

The current study had three main limitations. First, this was a retrospective study with a limited number of patients. It is possible that some potential biases and/or alpha errors affected the results of the current study. Second, the optimal evaluation for nutritional status in patients with cancer is unknown. The GNRI was used in the current study because it can be calculated using two simple values that are readily available in clinical practice. However, several other nutritional indexes using various combinations of factors in addition to (or instead of) albumin and body weight, such as prealbumin, cholesterol, neutrophil, lymphocyte, C-reactive protein, or body mass index, are also available [4]. Third, the current study evaluated cytotoxic chemotherapy. ICls are increasingly used as new standard treatments for cancers, including NSCLC [36, 37]. Furthermore, several regimens combining chemotherapy with one or more ICls have been developed [38,39]. It is reported that GNRI is associated with the efficacy of ICI monotherapy [40]. Thus, GNRI is expected to be predictive of the efficacy of novel combinations of chemotherapy and ICls. Further studies are needed to elucidate the predictive utility of the nutritional status and the optimal nutritional index for novel cancer therapies.

\section{Conclusions}

In conclusion, increased GNRI was associated with better PFS and OS following first-line platinum-based chemotherapy and second-line non-platinum therapy in patients with NSCLS independent of ECOG-PS. Assessments of nutritional status may be useful for predicting the efficacy of chemotherapy.

\section{Abbreviations}

\section{ALK}

anaplastic lymphoma kinase

Cl

confidence interval

ECOG-PS

Eastern Cooperative Oncology Group performance status

EGFR

epidermal growth factor receptor

GNRI

Geriatric Nutritional Risk Index

ICls

immune checkpoint inhibitors

NSCLC 
non-small-cell lung cancer

ORR

overall response rate

OS

overall survival

PFS

progression-free survival

\section{Declarations}

Ethics approval and consent to participate: The study protocol was approved by the Institutional Review Board of Hamamatsu University School of Medicine (No. 21-151). Patient consent was waved because this was a retrospective study.

Consent for publication: Not applicable

Availability of data and material: The datasets used and/or analyzed during the current study are available from the corresponding author on reasonable request.

Competing interests: All authors have no conflict of interest in relation to this manuscript.

Funding: This research did not receive any specific grant from funding agencies in the public, commercial, or not-for-profit sectors.

\section{Authors' contributions:}

Masato Karayama has full access to all of the data in the study and takes responsibility for the integrity of the data and the accuracy of the data analysis. Yusuke Inoue participated in study concept and design; acquisition, analysis and interpretation of data; statistical analyses; and drafting of the manuscript. Hideki Yasui, Hironao Hozumi, Yuzo Suzuki, Kazuki Furuhashi, Tomoyuki Fujisawa, Noriyuki Enomoto, and Yutaro Nakamura participated in study concept and design, interpretation of data, and drafting of the manuscript. Naoki Inui and Takafumi Suda participated in study concept and design, drafting of the manuscript, and supervision.

Acknowledgments: We thank Joe Barber Jr., PhD, from Edanz (https://jp.edanz.com/ac) for editing a draft of this manuscript.

\section{References}

1. Galmés S, Serra F, Palou A. Current state of evidence: Influence of nutritional and nutrigenetic factors on immunity in the COVID-19 pandemic framework. Nutrients. 2020;12:1-33.

2. Faverio P, De Giacomi F, Bodini BD, Stainer A, Fumagalli A, Bini F, et al. Nontuberculous mycobacterial pulmonary disease: an integrated approach beyond antibiotics. ERJ Open Res. 2021;7:00574-2020. 
doi:10.1183/23120541.00574-2020.

3. Healy C, Munoz-Wolf N, Strydom J, Faherty L, Williams NC, Kenny S, et al. Nutritional immunity: the impact of metals on lung immune cells and the airway microbiome during chronic respiratory disease. Respir Res. 2021;22:1-44. doi:10.1186/s12931-021-01722-y.

4. Baldessari C, Guaitoli G, Valoriani F, Bonacini R, Marcheselli R, Reverberi L, et al. Impact of body composition, nutritional and inflammatory status on outcome of non-small cell lung cancer patients treated with immunotherapy. Clin Nutr ESPEN. 2021;14:1-2.

5. Ramalho R, Rao M, Zhang C, Agrati C, Ippolito G, Wang FS, et al. Immunometabolism: new insights and lessons from antigen-directed cellular immune responses. Semin Immunopathol. 2020;42:279313.

6. Fearon KC, Voss AC, Hustead DS. Definition of cancer cachexia: Effect of weight loss, reduced food intake, and systemic inflammation on functional status and prognosis. Am J Clin Nutr. 2006;83:1345-50.

7. Vanhoutte G, Van De Wiel M, Wouters K, Sels M, Bartolomeeussen L, De Keersmaecker S, et al. Cachexia in cancer: what is in the definition? BMJ Open Gastroenterol. 2016;3:1-11.

8. Prado CMM, Baracos VE, McCargar LJ, Reiman T, Mourtzakis M, Tonkin K, et al. Sarcopenia as a determinant of chemotherapy toxicity and time to tumor progression in metastatic breast cancer patients receiving capecitabine treatment. Clin Cancer Res. 2009;15:2920-6.

9. Ross PJ, Ashley S, Norton A, Priest K, Waters JS, Eisen T, et al. Do patients with weight loss have a worse outcome when undergoing chemotherapy for lung cancers? Br J Cancer. 2004;90:1905-11.

10. Temel JS, Abernethy AP, Currow DC, Friend J, Duus EM, Yan Y, et al. Anamorelin in patients with nonsmall-cell lung cancer and cachexia (ROMANA 1 and ROMANA 2): results from two randomised, double-blind, phase 3 trials. Lancet Oncol. 2016;17:519-31. doi:10.1016/S1470-2045(15)00558-6.

11. Wang Z, Aguilar EG, Luna JI, Dunai C, Khuat LT, Le CT, et al. Paradoxical effects of obesity on T cell function during tumor progression and PD-1 checkpoint blockade. Nat Med. 2019;25:141-51.

12. Sooriyaarachchi M, Narendran A, Gailer J. Comparative hydrolysis and plasma protein binding of cisplatin and carboplatin in human plasma in vitro. Metallomics. 2011;3:49-55.

13. Park CR, Kim HY, Song MG, Lee Y. Efficacy and safety of human serum albumin - cisplatin complex in U87MG xenograft mouse models. 2020; li.

14. Liang $Y, X u L$, Yang $H, X u W, H u R$, Fan $X$, et al. Analysis on the interaction and binding properties of daphnoretin and human serum albumin in the presence of cisplatin: multi-spectroscopic methods and docking simulation. Eur J Pharm Sci. 2021;159:1-2.

15. Bouillanne O, Morineau G, Dupant C, Coulombel I, Vincent JP, Nicolis I, et al. Geriatric Nutritional Risk Index: A new index for evaluating at-risk elderly medical patients. Am J Clin Nutr. 2005;82:777-83.

16. Matsukuma Y, Tanaka S, Taniguchi M, Nakano T, Masutani K, Hirakata H, et al. Association of geriatric nutritional risk index with infection-related mortality in patients undergoing hemodialysis: The Q-Cohort Study. Clin Nutr. 2019;38:279-87. 
17. Wei L, Xie H, Li J, Li R, Chen W, Huang L, et al. The prognostic value of geriatric nutritional risk index in elderly patients with severe community-acquired pneumonia: A retrospective study. Medicine (Baltimore). 2020;99:e22217.

18. Dong $\mathrm{CH}$, Chen SY, Zeng HL, Yang B, Pan J. Geriatric nutritional risk index predicts all-cause mortality in patients with heart failure: A systematic review and meta-analysis. Clinics. 2021;76:1-7.

19. Matsumura T, Mitani Y, Oki Y, Fujimoto Y, Ohira M, Kaneko H, et al. Comparison of Geriatric Nutritional Risk Index scores on physical performance among elderly patients with chronic obstructive pulmonary disease. Hear Lung J Acute Crit Care. 2015;44:534-8.

20. Kanno H, Goto Y, Sasaki S, Fukutomi S, Hisaka T, Fujita F, et al. Geriatric nutritional risk index predicts prognosis in hepatocellular carcinoma after hepatectomy: a propensity score matching analysis. Sci Rep. 2021;11:9038. doi:10.1038/s41598-021-88254-z.

21. Tang Q-N, Qiu H-Z, Sun X-Q, Guo S-S, Liu L-T, Wen Y-F, et al. Geriatric nutritional risk index as an independent prognostic factor in locally advanced nasopharyngeal carcinoma treated using radical concurrent chemoradiotherapy: a retrospective cohort study. Ann Transl Med. 2021;9:532-532.

22. Chang LW, Hung SC, Li JR, Chiu KY, Yang CK, Chen CS, et al. Geriatric Nutritional Risk Index as a Prognostic Marker for Patients With Metastatic Castration-Resistant Prostate Cancer Receiving Docetaxel. Front Pharmacol. 2021;11 January:1-8.

23. Wiedermann CJ. Hypoalbuminemia as surrogate and culprit of infections. Int J Mol Sci. 2021;22.

24. Ferrer R, Mateu X, Maseda E, Yébenes JC, Aldecoa C, De Haro C, et al. Non-oncotic properties of albumin. A multidisciplinary vision about the implications for critically ill patients. Expert Rev Clin Pharmacol. 2018;11:125-37.

25. Erpenbeck L, Schön MP. Neutrophil extracellular traps: Protagonists of cancer progression? Oncogene. 2017;36:2483-90.

26. Neubert E, Senger-Sander SN, Manzke VS, Busse J, Polo E, Scheidmann SEF, et al. Serum and serum albumin inhibit in vitro formation of Neutrophil Extracellular Traps (NETs). Front Immunol. 2019;10 JAN.

27. Augustin RC, Delgoffe GM, Najjar YG. Characteristics of the tumor microenvironment that influence immune cell functions: Hypoxia, oxidative stress, metabolic alterations. Cancers (Basel). 2020;12:117.

28. Maj T, Wang W, Crespo J, Zhang H, Wang W, Zhao L, et al. Oxidative stress controls regulatory T cell apoptosis and suppressor activity and PD-L1-blockade resistance in tumor. Nat Immunol. 2018;18:1332-41.

29. Okadome K, Baba Y, Yagi T, Kiyozumi Y, Ishimoto T, Iwatsuki M, et al. Prognostic Nutritional Index, Tumor-infiltrating Lymphocytes, and Prognosis in Patients with Esophageal Cancer. Ann Surg. 2020;271:693-700.

30. Kitahara H, Shoji F, Akamine T, Kinoshita F, Haratake N, Takenaka T, et al. Preoperative prognostic nutritional index level is associated with tumour-infiltrating lymphocyte status in patients with surgically resected lung squamous cell carcinoma. Eur J Cardio-Thoracic Surg. 2021;17:1-2. 
31. Kishton RJ, Sukumar M, Restifo NP. Metabolic regulation of T cell longevity and function in tumor immunotherapy. Cell Metab. 2017;26:94-109.

32. Mok EHK, Lee TKW. The pivotal role of the dysregulation of cholesterol homeostasis in cancer: Implications for therapeutic targets. Cancers (Basel). 2020;12:1410.

33. Dyck L, Lynch L. Cancer, obesity and immunometabolism - Connecting the dots. Cancer Lett. 2018;417:11-20.

34. Alan R Tall, Yvan-Chrvet L. Cholesterol, inflammation and innate immunity. Nat Rev Immunol. 2015;15:104-16.

35. Newton R, Priyadharshini B, Turka LA. Immunometabolism of regulatory T cells. Nat Immunol. 2016;17:618-25.

36. Borghaei H, Paz-Ares L, Horn L, Spigel DR, Steins M, Ready NE, et al. Nivolumab versus docetaxel in advanced nonsquamous non-small-cell lung cancer. N Engl J Med. 2015;373:1627-39.

37. Brahmer J, Reckamp KL, Baas P, Crinò L, Eberhardt WEE, Poddubskaya E, et al. Nivolumab versus docetaxel in advanced squamous-cell non-small-cell lung cancer. N Engl J Med. 2015;373:123-35.

38. Gandhi L, Rodríguez-Abreu D, Gadgeel S, Esteban E, Felip E, De Angelis F, et al. Pembrolizumab plus chemotherapy in metastatic non-small-cell lung cancer. N Engl J Med. 2018;378:2078-92.

39. Hellmann MD, Paz-Ares L, Bernabe Caro R, Zurawski B, Kim S-W, Carcereny Costa E, et al. Nivolumab plus Ipilimumab in Advanced Non-Small-Cell Lung Cancer. N Engl J Med. 2019;381:2020-31.

40. Sonehara K, Tateishi K, Araki T, Komatsu M, Yamamoto H, Hanaoka M. Prognostic value of the geriatric nutritional risk index among patients with previously treated advanced non-small cell lung cancer who subsequently underwent immunotherapy. Thorac Cancer. 2021;12:1366-72.

\section{Figures}

A

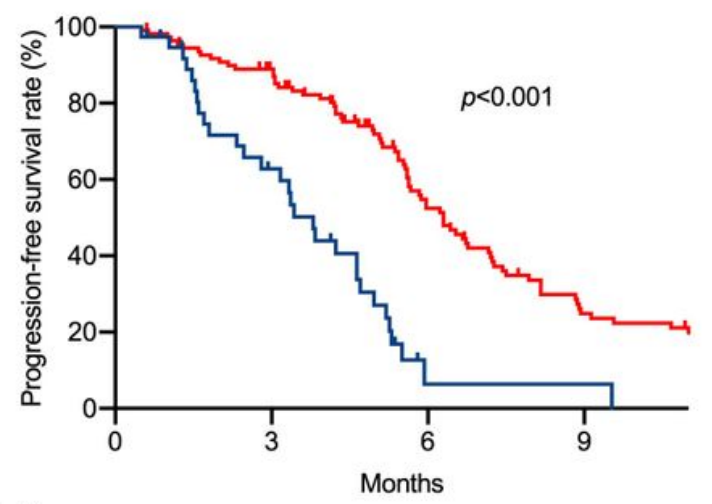

No. at risk High GNRI 110 Low GNRI 38
94

21

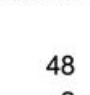

48
2
B

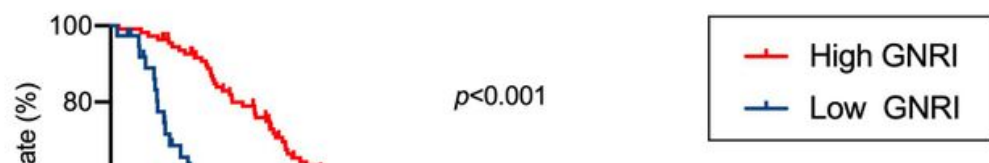

No. at risk

High GNRI 110 Low GNRI 38

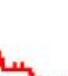

票

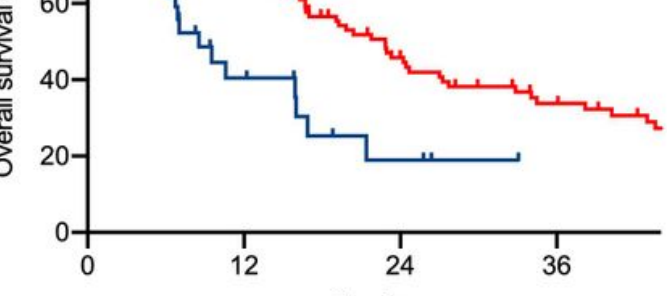

Months

Figure 1 
Progression-free and overall survival after first-line platinum-based chemotherapy according to the Geriatric Nutritional Risk Index (GNRI) Kaplan-Meier curves of A) progression-free survival and B) overall survival according to the GNRI. Blue and red lines indicate low and high GNRI, respectively.

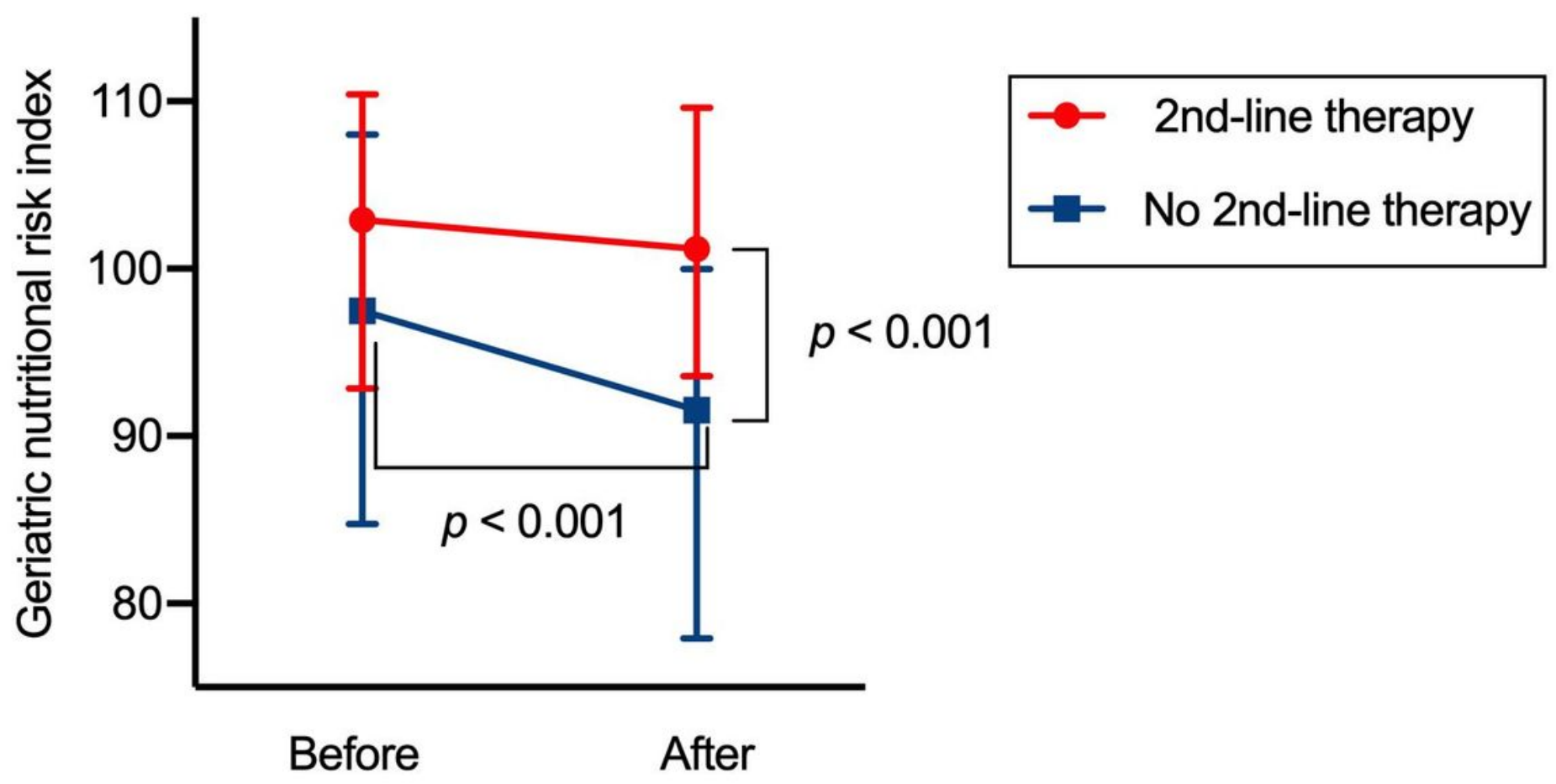

Figure 2

Changes in the Geriatric Nutritional Risk Index between before and after first-line platinum-based chemotherapy Dots and error bars indicate the median and interquartile range, respectively. Red and blue lines indicate patients who did and did not receive second-line chemotherapy, respectively.

A

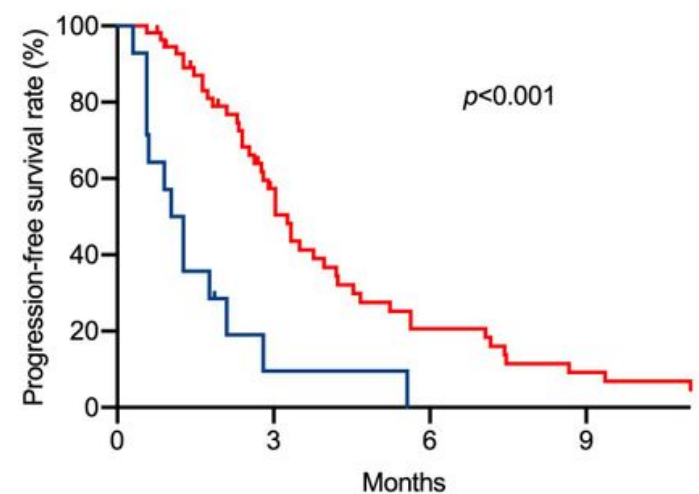

No. at risk High GNRI 56 Low GNRI 14

\section{6}

B

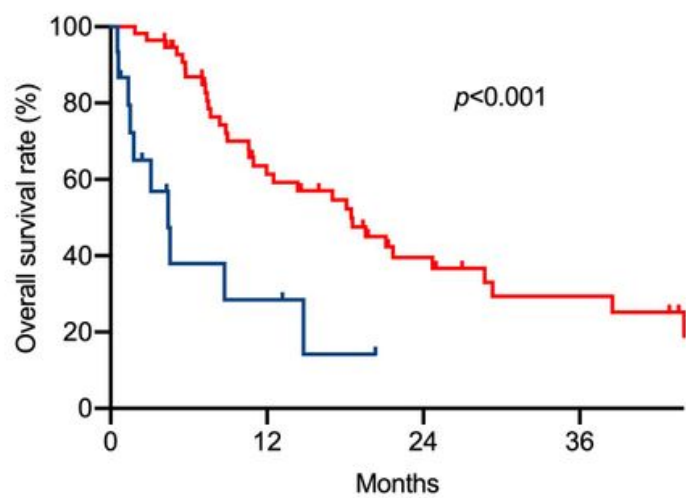

No. at risk High GNRI 56 Low GNRI 15

\section{- High GNRI \\ - Low GNRI}

Figure 3 
Progression-free and overall survival after second-line non-platinum chemotherapy according to the Geriatric Nutritional Risk Index (GNRI) Kaplan-Meier curves of A) progression-free survival and B) overall survival according to the GNRI. Blue and red lines indicate low and high GNRI, respectively.

\section{Supplementary Files}

This is a list of supplementary files associated with this preprint. Click to download.

- SupplementaryFigures.pdf 